\title{
THE EFFECTS OF CURRENT TRENDS ON THE DEVELOPMENT FACTORS OF INDUSTRY 4.0 AND FACTORIES OF THE FUTURE (FOF)
}

\author{
Dragan Vuksanović1, \\ Jelena Vešić \\ Dragan Cvetković ${ }^{2}$
}

\author{
${ }^{1}$ Singidunum University, \\ Belgrade, Serbia \\ ${ }^{2}$ Faculty of Informatics and Computing, \\ Singidunum University, \\ Belgrade, Serbia
}

\begin{abstract}
:
This paper gives a literature overview and states the effects of current economic trends on the development factors of Industry 4.0 and Factories of the Future (FoF). The application of new technology based on cyber-physical systems and the Internet leads to significant improvements such as increase of automation and shorter period between the development of a new product and its market launch.
\end{abstract}

Keywords:

Industry 4.0, Factory of the Future (FoF), Smart Factory, Internet of Things (IoT), Logistics 4.0 .

\section{INTRODUCTION}

The world around us has been changing on a daily basis along with development of human civilization. Therefore, technical and technological developments of production are changing as well. We are all now familiar with today's concept of "smart": smart phones, smart TV, smart cities, smart factories, smart medicine, smart cars, smart railways, etc.

Industry 4.0, as shown in Image 1, is a model that shows how industrial production follows the latest developments and changes over time. Thereby, the man, machine and the production itself constitute the force in one intelligent and independent network.

The main driver of each industry is regulated transport and road network. Today, the most developed countries of the world want to economically dominate the world trade by developing railways and other high-quality transport systems.

Why is this important? You can produce the best product in the world, but if you cannot transport the product to the customer in the shortest possible period of time, you cannot survive at global market, and you lose the customers.

Simply, Factories of the Future (FoF) and the Industry 4.0 must be accompanied by high quality and reliable transport system.

In the following images the examples of planning two major railway lines in the world are shown. The first relates to the Integration of the Trans Siberian Rail into Euroasian Rai Network (Image 2). 


\section{Industry $\mathbf{4 . 0}$ is a journey towards a complete value chain transformation driven by new technologies and new collaborative business models}

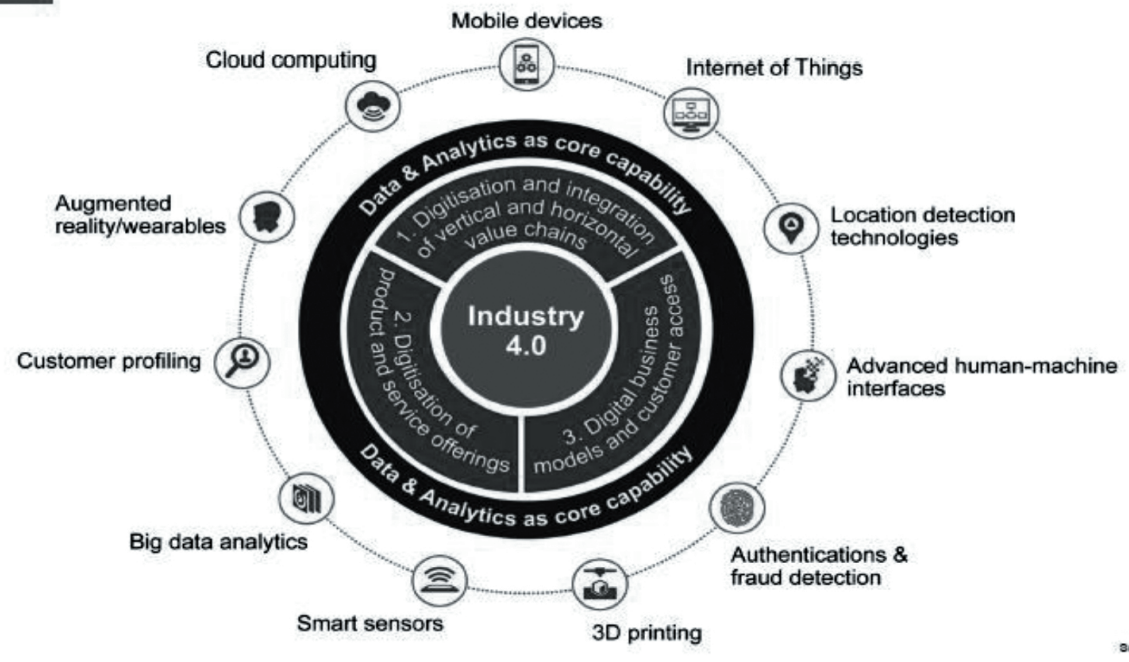

Image 1. Industry 4.0, taken from [2].

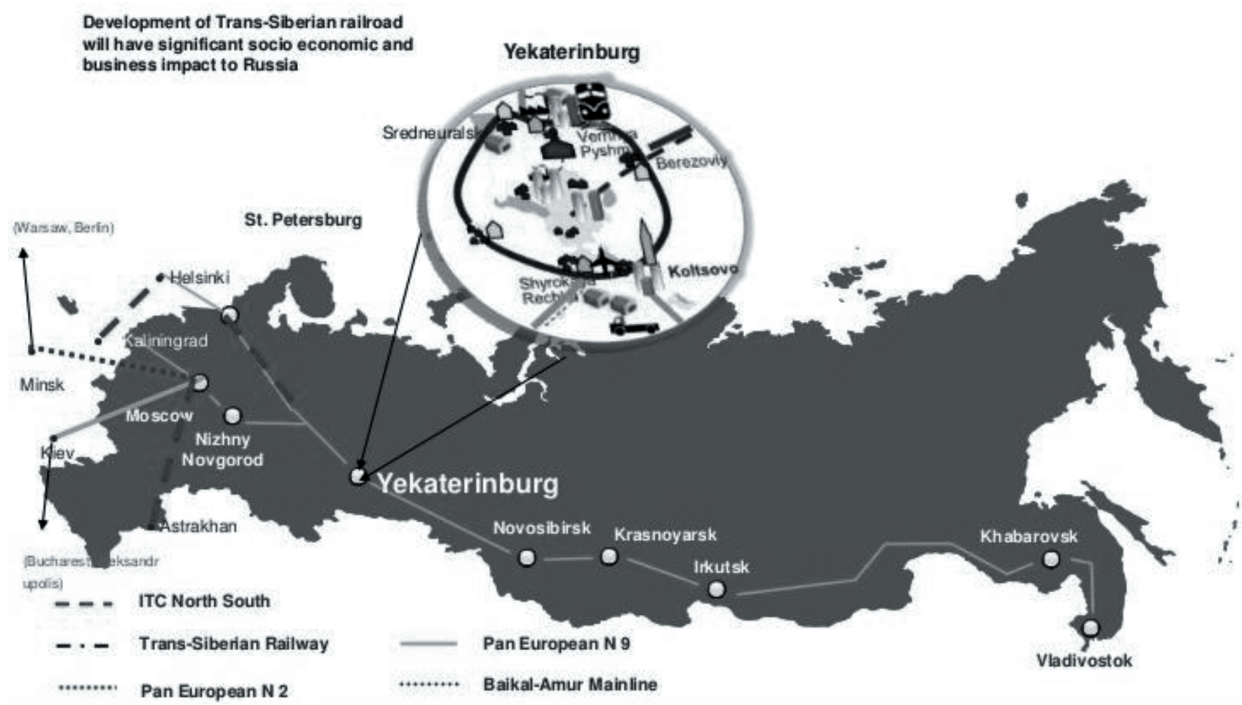

Image 2. Integration of the Trans Siberian Rail into Euroasian Rai Network, taken from [1].

Image 3 represents the plans for building new railway project. The project name is Chinese renewing "Silk Road" and its purpose is to economically connect Asian and Arab peninsula with Europe. There are 3 possible routes of new Silk Road:

- Northern Route: 10-16 days (Between 6000 km and $7700 \mathrm{~km}$ )

- Central Route: 13-18 days (Between $5300 \mathrm{~km}$ and $6000 \mathrm{~km}$ )

- Southern Route: 8-17 days (Between 4500 km and $6200 \mathrm{~km}$ ).

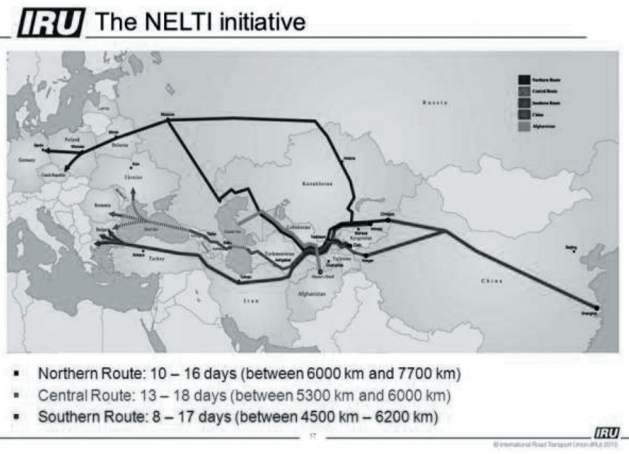

Image 3. The silk road railway, taken from [1]. 


\section{MEGA TRENDS OF THE FUTURE}

So, is it possible to know what the future will look like? The authors Frost \& Sullivan have defined so called mega trends - transformative, global forces that define the future world with their far reaching impacts on businesses, societies, economies, cultures, and personal lives. According to them, [3] there are top 10 mega trends of the future:

1. Urbanization: Mega Cities, Mega Regions, Mega Corridors, Smart Cities;

2. E-Mobility;

3. Social Trends: Geo Socialization, Generation Y and Reverse Brain Drain;

4. SPACE JAM: Congested Satellite Orbits;

5. World War 3: Cyber Warfare;

6. RoboSlaves;

7. Virtual World: Fluid Interfaces and Haptic Technology;

8. Innovating to Zero!: Zero Emission Technologies;

9. Emerging Transportation Corridors;

10. Health, Wellness and Well-Being.

According to Bitkom (a German IT association) and their Managing Director Dr. Bernhard Rohleder's prediction [8], global ICT markets will probably once again grow faster than the economy as a whole. In just a few years, most data will be coming from emerging markets such as China and India.

According to the study conducted by the market research and consulting firm International Data Corporation (IDC) [8], these markets will cover 62 percent of the digital universe in 2020 (expected to consist of 40 zettabytes of data). IDC estimates that in 2020 nearly 40 percent of all data will come into contact with cloud computing at some point between its creation and use. As a result, the number of cloud servers will grow tenfold worldwide.

The U.S. software firm Symantec found out that only 17 percent of more than 3,000 companies surveyed worldwide used cloud storage in 2013. There is a big difference in usage figures for large companies (26 percent) and small and medium-size enterprises (7 percent). Symantec states that the main reason why companies decide not to use cloud computing is their fear of hidden costs.

Another study done by Booz \& Company [8], Navigating the Digital Future, shows that companies worldwide spend an average of 8.1 percent of their research and development budgets on digital tools. The percentages were highest among the sectors for software/Internet, aerospace/defense and healthcare. The ten most important technology trends include the modernization of infrastructure and the use of mobile devices such as smartphones and tablet computers.

The Fraunhofer Institute for Industrial Engineering (IAO) study [8], showed that less than one fourth of the businesses, which had been surveyed in Germany, were either highly or fully automated. According to the respondents, the main obstacles to the creation of a smart factory are still unresolved questions concerning IT security, a lack of standards, higher education level of the personnel, insufficient performance of the information and communications infrastructure, as well as high investment costs.

A great example of the application of Digital Geography in the world is shown in Image 4.

According to Nick Johnes, Gartner's vice president and distinguished analyst, 10 trends and predictions for the Future of IoT are [5]:

1. Platforms,

2. Standards and Ecosystems,

3. Event Stream Processing,

4. Operating Systems,

5. Processors and Architecture,

6. Low-Power, Wide-Area Networks,

7. Low-Power, Short-range IoT Networks,

8. Device (Thing) Management,

9. Analytics,

10. Security.

Image 5 represents the example of estimated data growth in various categories and overall, and Image 6 shows the IoT security [5].

\section{KEY SUCCESS FACTORS FOR INDUSTRY 4.0}

There are five Key Success Factors for Industry 4.0 [2]:

1. Start with the people - Management should entitle a responsible person/team for the digital transformation. Management commitment and training/ education is absolutely the key.

2. Begin digitalizing, step by step - Start with the first digital processes to learn and adopt change. Combine technology strategies with your business model and resources.

3. Learn from your clients and peers - Focus your key clients' changing needs in your digital transformation process. Listen to and learn from your clients and best peers in your industry. 
4. Collaborate and share best practice - Do not underestimate the power of working together; build a strong ecosystem with partners. Share experience and best practice and learn from digital markets. Use social media, online communities and online channels to promote your products or services.
5. Do not wait, act now - New disruptive business models can change clients' needs very fast. Do your homework and digital assessment now.

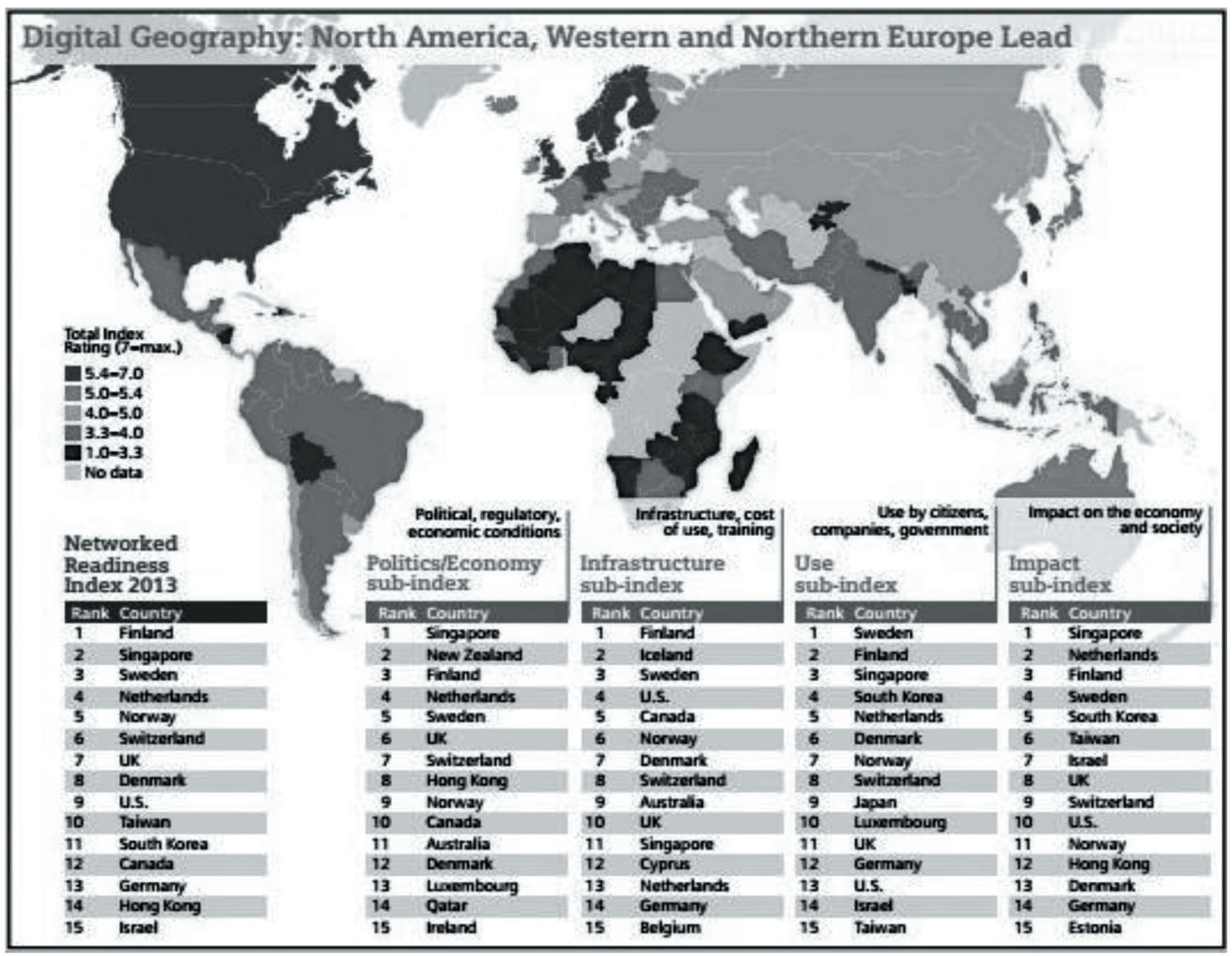

Image 4. Digital Geography: North America, Western and Northern Europe, taken from [4].

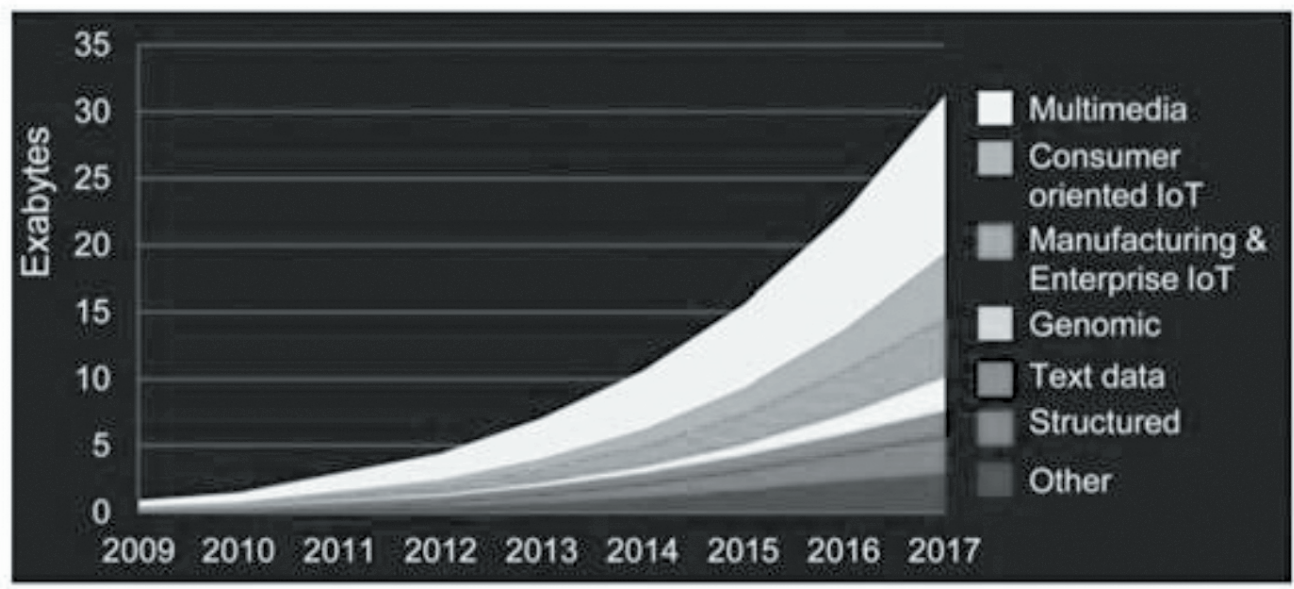

Image 5. Estimated data growth in various categories and overall, taken from [5]. 


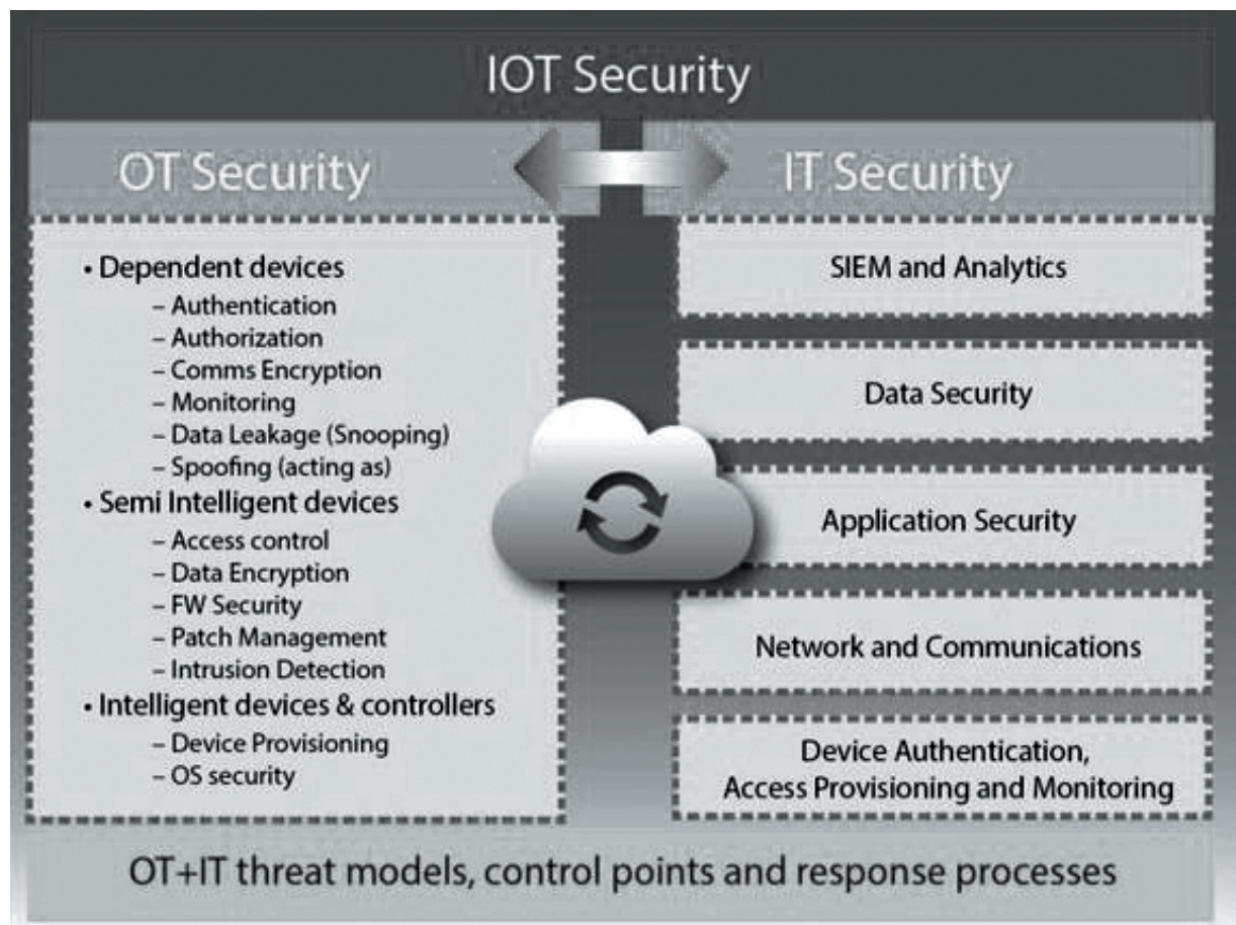

Image 6. IoT Security, taken from [5].

\section{GLOBAL MANUFACTURING COMPETITIVENESS INDEX}

According to Deloitte the main factors for Global Manufacturing Competitiveness Index for the year 2016 were [6]:

1. Global Manufacturing Competitiveness Index, Country rankings

2. Examining the drivers of global manufacturing competitiveness - As in prior GMCI reports, Talent drives manufacturing competitiveness, executives responding to the 2016 global CEO survey were asked to rank the key government and market forces that drive global manufacturing competitiveness. Study results show that countries that do well across several of these categories are generally ranked higher than those nations that excel in only one or two of the top drivers. The drivers of global manufacturing competitiveness are shown in image 7 [6].

In order to understand the comparative strengths and weaknesses of some of the most competitive nations, global manufacturing CEOs were asked to rate six focus nations - the United States, Germany, Japan, South Korea, China, and India, based on 6 of 12 drivers of competitiveness. They made a mosaic of strengths and weaknesses for these 6 countries. The following section explores each driver and makes unique contribution to shaping the overall global manufacturing landscape.

This mosaic shows the competitive advantage of Germany, the United States and Japan on most of the top drivers including talent, innovation policy and infrastructure. These results are direct consequence of regulated procedures. Also, strong legal and regulatory foundation paired with a reliable physical infrastructure in these countries enables advanced nations to lead the world in overall manufacturing competitiveness. In addition, the survey results reveal that China and India still hold a significant competitive advantage when it comes to the cost of labor and materials. On the other hand, these two countries are among the least competitive global nations in respect to their legal and regulatory environments, while India has a problem with its poor physical infrastructure.

3. Competitiveness of trade exports [6] - Competitiveness of trade exports is the key determinant of overall country competitiveness and prosperity. Nations that are able to competitively export higher value, advanced manufacturing and technology intensive products have higher overall prosperity.

Image 9 represents the supplemental analysis: Top 10 future most competitive nations and their top five export partners [6]. 


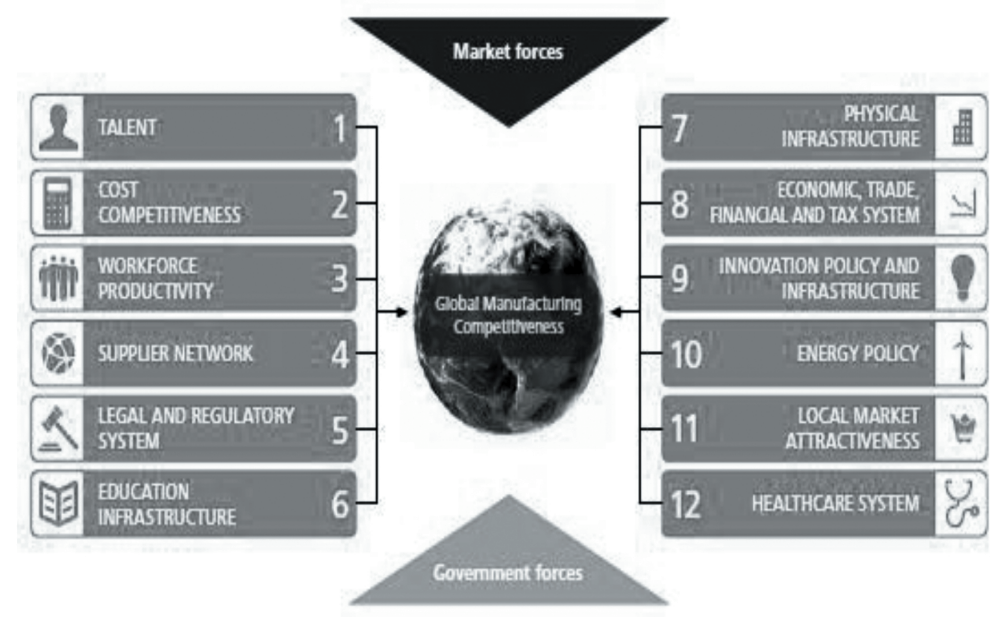

Image 7. Examining the drivers of global manufacturing competitiveness, taken from [6].

Linking drivers of competitiveness and country performance

\begin{tabular}{|c|c|c|c|c|c|c|}
\hline $\begin{array}{l}\text { Selecteded country manufacturing } \\
\text { competilveness drivers }\end{array}$ & Unitted States & Germany & \begin{tabular}{|l|} 
Japan \\
\end{tabular} & $\underbrace{}_{\text {south Korea }}$ & $\begin{array}{l}\vdots \\
\text { China }\end{array}$ & \begin{tabular}{|l} 
Indla \\
\end{tabular} \\
\hline TALENT & 89.5 & 97.4 & 88.7 & 64.9 & 55.5 & 51.5 \\
\hline $\begin{array}{l}\text { INNOVATION POLICY } \\
\text { AND INFRASTRUCTURE }\end{array}$ & 98.7 & 93.9 & 87.8 & 65.4 & 47.1 & 32.8 \\
\hline $\begin{array}{l}\text { COST } \\
\text { COMPETIIIVENESS }\end{array}$ & 39.3 & 37.2 & 38.1 & 59.5 & 96.3 & 83.5 \\
\hline$\uparrow$ ENERGY POUCY & 68.9 & 66.0 & 62.3 & 50.1 & 40.3 & 25.7 \\
\hline $\begin{array}{ll}\text { 要 PHYSICAL } \\
\text { INFRASTRUCTURE }\end{array}$ & 90.8 & 100.0 & 89.9 & 69.2 & 55.7 & 10.0 \\
\hline $\begin{array}{l}\text { LEGALAND REGULATORY } \\
\text { ENVIRONMENT }\end{array}$ & 88.3 & 89.3 & 78.9 & 57.2 & 24.7 & 18.8 \\
\hline
\end{tabular}

Image 8. Global CEO survey: Focus country performance by key competitiveness drivers, taken from [6].

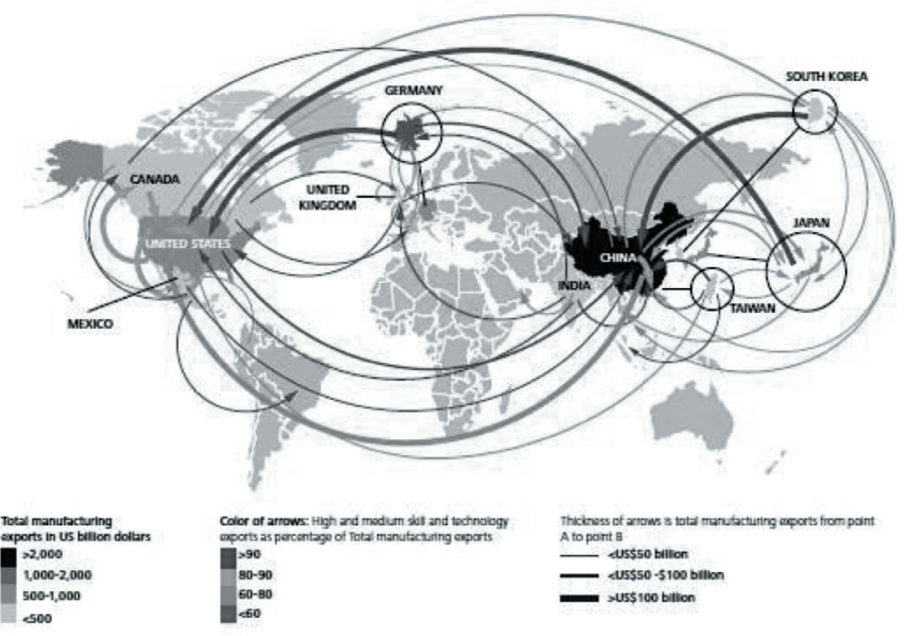

Image 9. Supplemental analysis: Top 10 future most competitive nations and their top five export partners, taken from [6]. 


\section{CONCLUSION}

Industry 4.0 is new Industrial revolution of the 21 st century, which enables companies to create "smarter" products and services by reducing costs and increasing efficiency where the human factor is crucial for the application. The work is based on the existing literature in the field. The world is currently facing several "megatrends" (demographic, urbanization, health, globalization, mobility, climate change, etc.) that will have strong and far-reaching economic, environmental and social consequences on societies and governments.

The creation of new economic strength for Serbia and the benefits of Industry 4.0 can be reached only through a concerted pan-Balkan, pan-European or pan-World strategy. The emergence of "digitalization" and "knowledge society" trends are at the core of a new business environment - The Economy 4.0 and therein, the Industry 4.0. This means that companies have to invest into new technologies including big data, the internet of things, new smart system of transportation and logistics, but also into the education of skilled workforce, which altogether need to be accompanied by innovative forms of governance.

New "smart" Industry 4.0 requires new modern generation of "smart" people with smart "thinking".

\section{REFERENCES}

[1] 9th WORLD CARGO SIMPOSIUM SHANGAI, 10-12 MARCH 2015 https://www.iata.org/events/ wcs/Documents/wcs2015-Supply-Chain-Management-presentation.pdf

[2] Whitepaper - Opportunities for the Swiss Export Industry, April 2016 INDUSTRY 4.0, 23.02.2017. https://www.sge.com/sites/default/files/cserver/static/downloads/SGE_Whitepaper_Indus try40_2016_final.pdf
[3] Sarwant Singh, FROST\&SULLIVAN Top 20 Global Mega Trends To and their impact to the Business, Society and Cultures, 23.02.2017. www.frost.com/ $\mathrm{prod} / \mathrm{servlet} / \mathrm{cpo} / 213016007$

[4] Siemens, Pictures of the Future The Magazine for Research and Innovation, Spring 2014, 23.02.2017. Digital Transformation| Facts and Forecasts The Economic Impact of Digital Expansion https:// www.siemens.com/content/dam/inter net/siemens-com/innovation/pictures-of-the- future/pofarchive/pof-spring-2014.pdf

[5] 10 Predictions for the Future of IoT, Ahmed Banafa, 23.02.2017. https://www.bbvaopenmind.com/ en/10-predictions-for-the-future-of-iot/

[6] Delloite, Global Manufacturing Competitiveness Index 2016, 23.02.2017. https://www2.deloitte.com/ content/dam/Deloitte/global/Documents/Manufacturing/gx- global-mfg-competitiveness-index-2016. pdf

[7] REPORT TO THE PRESIDENT Technology and the Future of Cities Executive Office of the President President's Council of Advisors on Science and Technology February 2016, 23.02.2017. https:// www.whitehouse.gov/sites/whi tehouse.gov/files/ images/Blog/PCAST\% 20Cities\%20Report\%20 _\%20FINAL.pdf

[8] From Big Data to Smart Data Facts and Forecasts: The Economic Impact of Digital Expansion https:// www.siemens.com/innovation/en/ho me/picturesof-the-future/digitalization-and- software/frombig-data-to-smart-data-facts- and-forecasts.html

[9] Jahresbilanz: Digitale Agenda der Bundesregierung zu einem Viertel umgesetzt https://www.bitkom. org/Presse/Presseinf ormation/Jahresbilanz-Digitale-Agenda- der-Bundesregierung-zu-einem-Viertel- umgesetzt.html 